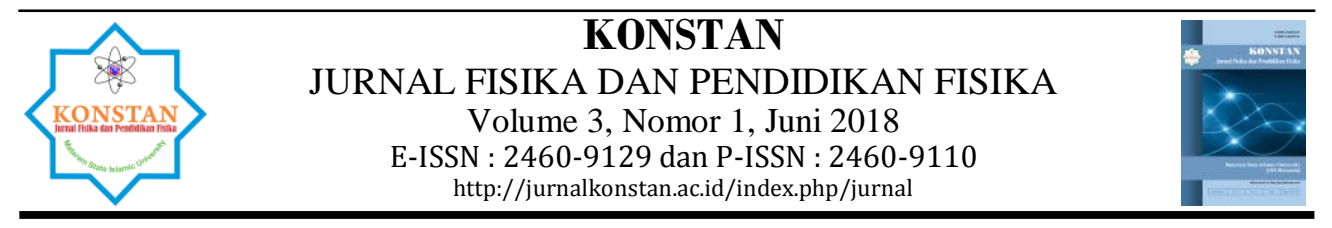

\title{
IDENTIFIKASI KETERAMPILAN PROSES SAINS SISWA MAN 2 KOTA MATARAM KELAS XI-A MATA PELAJARAN FISIKA TAHUN 2017
}

\author{
M. Isnaini ${ }^{1 *}, \operatorname{Ramlah}^{1}$, Evi Sri Erwinta ${ }^{1}$ \\ ${ }^{1}$ Pendidikan Fisika Universitas Muhammadiyah Mataram, Jln. KH. Ahmad Dahlan No. 1, \\ Mataram, NTB, Indonesia.
}

\section{Info Artikel}

Sejarah Artikel:

Diterima Juni 2018

Disetujui Juli 2018

Dipublikasikan Juli 2018

Kata Kunci:

Instrumen assesment, Keterampilan proses sains, fluida statis

\begin{abstract}
Abstrak
Telah dilakukan identifikasi untuk mengetahui aspek keterampilan proses sains apa saja yang dimiliki siswa MAN

2 Kota Mataram Kelas XI-A. Instrumen yang digunakan dalam penelitian ini adalah tes KPS pilihan ganda dan angket respon. Tes KPS dilakukan sebanyak dua kali untuk melihat konsistensi aspek KPS yang dimiliki siswa. Instrumen KPS yang digunakan telah kembangkan dan diuji cobakan. Berdasarkan data penelitian diperoleh aspek KPS yang dominan dimiliki siswa MAN 2 Kota Mataram kelas XI-A adalah Observasi 65\%, Klasifikasi 75\%, Interpretasi 65\%, Prediksi 52\%, Komunikasi 82\%, Hipotesis 69\%, Merencanakan Penelitian 82\%, dan Aplikasi konsep 68\%. Tanggapaan guru terhadap Instrumen Assessment Keterampilan Proses Sains sangat baik dengan tingkat kesesuaian isi sebesar $90 \%$ mendapatkan kategori sangat tinggi, aspek konstruksi $80 \%$ mendapatkan kategori sangat tinggi, dan aspek keterbacaan 80\% mendapatkan kategori sangat tinggi
\end{abstract}

(C) 2018 Universitas Islam Negeri Mataram

\footnotetext{
* Corresponding Author: iskasipahune@gmail.com

Alamat korespodensi:

Gedung Pasca Sarjana Lantai 3 Kampus 2 UIN Mataram, Jl. Gajah Mada 100 Jempong Mataram, Indonesia

Email: jurnalkonstan@uinmataram.ac.id
} 


\section{PENDAHULUAN}

Terdapat keprihatian dunia pendidikan terhadap literasi sains siswa sekolah. Hasil terbaru PISA (Programme in International Student Assessment) dan TIMSS (Trend International Mathematics and Science Study ) 2015 menunjukkan Indonesia berada pada posisi 62 dari 70 negara (untuk PISA) dan urutan ke 44 dari 47 negara (TIMSS) . Hal ini menjadi salah satu gambaran kemampuan literasi sains siswa di Indonesia masih sangat rendah.

Pemerintah telah melakukan berbagai upaya untuk terus meningkatkan tingkat literasi sains, salah satunya melalui perubahan kurikulum 2013. Titik tolak K13 adalah pembelajaran diarahkan untuk dapat mengembangkan hard skill dan soft skill siswa dengan penguasaan kompetensi meliputi ranah kognitif, afektif, dan psikomotorik.

Tabel 1 Pendekatan Pembelajaran

\begin{tabular}{lll}
\hline NO & \multicolumn{1}{c}{ ASPEK KPS } & \multicolumn{1}{c}{ INDIKATOR KPS } \\
\hline 1. & $\begin{array}{l}\text { Merumuskan } \\
\text { Hipotesis }\end{array}$ & $\begin{array}{l}\text { Merumuskan dugaan yang masuk akal yang } \\
\text { dapat diuji tentang bagaimana atau mengapa } \\
\text { sesuatu terjadi. }\end{array}$ \\
\hline 2. & Merencanakan percobaan & $\begin{array}{l}\text { Merancang rosedur percobaan yang sesuai, } \\
\text { siswa mampu merancang percobaan sesuai } \\
\text { hal-hal yang perlu diamati sehingga sesuai } \\
\text { dengan tujuan percobaan. }\end{array}$ \\
\hline 3. & Melakukan percobaan & $\begin{array}{l}\text { Memperhatikan kegunaan dan tingkat } \\
\text { ketelitian alat yang digunakan. } \\
\text { Melaksanakan prosedur pengukuran yang } \\
\text { telah dibuat dengan baik dan benar. }\end{array}$ \\
\hline 4. & Melakukan pengamatan & $\begin{array}{l}\text { Melakukan pengamatan dengan teliti, } \\
\text { memperhatikan dan mengendalikan variabel } \\
\text { tetap dan variabel tidak tetap. }\end{array}$ \\
\hline 5. & $\begin{array}{l}\text { Menginterprestasikan/ } \\
\text { Menafsirkan data }\end{array}$ & $\begin{array}{l}\text { Menganalisis hasil, menghubungkan variabel } \\
\text { (mencari pola hubungan yang ada) }\end{array}$ \\
\hline 6. & Memprediksi & $\begin{array}{l}\text { Menghubungkan data percobaan dengan teori } \\
\text { artinya siswa berfikir induksi untuk } \\
\text { menghubungkan antara apa yang diamati, } \\
\text { hasil pengamatan dan hipotesis yang diajukan. }\end{array}$ \\
\hline 7. & Menerapkan konsep & $\begin{array}{l}\text { Mengerjakan pertanyaan diskusi sesuai teori } \\
\text { yang ada }\end{array}$ \\
\hline 8 & Mengkomunikasikan & $\begin{array}{l}\text { Memperlihatkan hubungan anatara hasil } \\
\text { dengan tujuan dari percobaan. }\end{array}$ \\
\hline
\end{tabular}

Pendekatan yang digunakan dalam pembelajaran dengan menitik beratkan pada penggunaan metode ilmiah dalam kegiatan belajar mengajar dikenal dengan nama Scientific Approach (pendekatan ilmiah). Scientific Approach dalam pembelajaran IPA fisika dapat diterapkan melalui keterampilan proses sains.

Keterampilan proses sains merupakan kemampuan yang mendasar yang dimiliki, dikuasai dan diaplikasikan dengan suatu kegiatan ilmiah, sehingga para 
ilmuwan dapat menemukan sesuatu yang baru bahwa keterampilan proses melibatkan keterampilan intelektual, manual dan sosial. Keterampilan tersebut terlihat saat peserta didik menggunakan pikirannya, keterlibatan peserta didik dalam penggunaan alat dan bahan serta proses peserta didik ketika berinteraksi dengan sesamanya [1].

Keterampilan proses sains (KPS) merupakan keterampilan ilmiah yang digunakan untuk menemukan konsep atau prinsip dan teori dalam rangka mengembangkan konsep yang telah ada atau menyangkal penemuan sebelumnya.

Keterampilan proses sains mengajak siswa untuk memproses informasi baru melalui pengalaman konkret seperti kegiatan praktikum [2]. Kegiatan praktikum memberi kesempatan bagi peserta didik untuk mengalami sendiri, mencari kebenaran, atau mencoba mencari suatu hukum atau dalil, dan menarik kesimpulan atas proses yang dialaminya.

Bedasarkan hasil obervasi di MAN 2 Mataram ditemukan bahwa pendekatan KPS telah diterapkan akan tetapi penilaian pembelajaran fisika yang dilakukan oleh guru lebih ditekankan pada knowladge bukan keterampilan prosesnya. Sehingga muncul keingintahuan tentang aspek KPS apa saja yang dimiliki siswa kelas XI-A pada mata pelajaran fisika.

\section{METODE PENELITIAN}

Penelitian yang digunakan adalah deskriptif kualitatif, dilakukan pada kelas XI-A MAN 2 Kota Mataram. Instrument yang digunakan adalah tes KPS dan angket. Instrument tes KPS yang digunakan sebanyak 2 dengan materi fisika yang berbeda-beda. Instrumen KPS yang pertama menggunakan materi Hukum Newton dan yang kedua menggunakan materi Fluida Statis. Sebelum instrument KPS diberikan, instrument tersebut di ujicobakan untuk melihat kelayakan instrument tersebut. Kelayakan instrument dilihat dari validitas, relibilitas, tingkat kesulitan, daya beda.

\section{Uji Validitas}

Validitas butir soal dapat ditentukan dengan mencari korelasi product moment masing-masing soal berdasarkan skor item dengan skor total [3].

$$
r_{x y}=\frac{N \sum X Y-\left(\sum X\right) \cdot\left(\sum Y\right)}{\sqrt{\left\{N \sum X^{2}-\left(\sum X\right)^{2}\right\} \cdot\left\{N \sum Y^{2}-\left(\sum Y\right)^{2}\right\}}}
$$

Keterangan :

$\mathrm{r}_{\mathrm{xy}}=$ koefisien validitas ( $\mathrm{r}$ hitung)

$\mathrm{N} \quad=$ jumlah peserta tes

$\sum X=$ jumlah skor item soal tes

$\sum Y \quad=$ skor total peserta

Hasil $\mathrm{r}$ hitung/ $\mathrm{r}_{\mathrm{xy}}$ yang didapat kemudian di bandingkan dengan tabel $\mathrm{r}$ product moment yang disesuaikan dengan jumlah responden, dimana penggunaan $r$ tabel dengan pilihan taraf signifikansi. 


\section{Reliabilitas}

Reliabilitas tes bentuk uraian dapat dilakukan dengan menggunakan rumus Alpha Cronbach [3],

$\Sigma \sigma_{i}^{2}=$ jumlah varians tiap item

$$
r_{11}=\left(\frac{n}{n-1}\right)\left(1-\frac{\Sigma \sigma_{i}^{2}}{\sigma_{t}^{2}}\right)
$$

$=$ varians skor total

Jumlah varians skor tiap item dapat dihitung dengan menggunakan rumus sebagai berikut [3] :

$$
\sigma_{i}^{2}=\frac{\Sigma X_{i}^{2}-\frac{\left(\Sigma X_{i}\right)^{2}}{n}}{n}
$$

Varians total dapat dihitung dengan menggunakan rumus sebagai berikut [3]

$$
\sigma_{t}^{2}=\frac{\Sigma Y_{t}^{2}-\frac{\left(\Sigma Y_{t}\right)^{2}}{n}}{n}
$$

Keterangan :

$=$ varians tiap soal

= varians total

= jawaban responden untuk setiap butir soal

$=$ total jawaban responden untuk setiap butir pertanyaan

$\mathrm{n}=$ jumlah peserta didik

\section{Daya Pembeda Tes}

Daya Pembeda adalah kemampuan tes untuk membedakan antara peserta didik yang pandai dan bodoh; Artinya, jika tes tersebut diberikan pada anak yang tergolong pandai akan lebih banyak dapat dijawab dengan benar. Sedangkan jika diberikan kepada peserta didik yang tergolong bodoh akan lbih banyak dijawab salah. Daya pembeda tes yang baik adalah antara 20\% - 80\% atau antara 30\% $70 \%$.

Rumus untuk menghitung tingkat daya beda tes adalah sebagai berikut [4],

$$
D_{P}=\frac{\sum\left(P_{A}-P_{B}\right)}{n}
$$

\section{Dengan :}

= Daya beda tes

$\mathrm{N}=$ Jumlah butir soal 
Rumus untuk menghitung daya beda butir tes adalah sebagai berikut [4] :

$$
D_{B}=\frac{n B_{A}}{n_{A}}-\frac{c}{n_{B}}
$$

Keterangan :

$=$ jumlah subyek yang menjawab betul pada kelompok atas

$=$ jumlah subyek yang menjawab betul pada kelompok bawah

$=$ jumlah subyek kelompok atas

$=$ jumlah subyek kelompok bawah

Tabel 2. Kriteria Daya Beda (D)

\begin{tabular}{cc}
\hline Nilai & Keterangan \\
\hline $0,00-0,19$ & kurang baik \\
\hline $0.20-0.39$ & cukup baik \\
\hline $0.41-0,70$ & baik \\
\hline $0,71-1,00$ & sangat baik \\
\hline
\end{tabular}

Untuk menghitung persentase jawaban angket pada setiap item dengan menggunakan rumus sebagai berikut:

$$
\% X_{\text {in }}=\frac{\sum S}{S_{\text {maks }}} x 100 \%
$$

Keterangan :

$\%$ Xin = Persentase jawaban angket-i asesmen keterampilan proses sains pada materi Fluida Statis

$\sum S \quad=$ Jumlah skor jawaban

Smaks = Skor maksimum yang diharapkan

Menghitung rata-rata persentase angket untuk mengetahui tingkat kelayakan dan keterbacaan instrumen asesmen berbasis keterampilan proses sains dengan rumus sebagai berikut:

$$
\overline{\% X_{2}}=\frac{\sum \% X_{\text {in }}}{n}
$$

Keterangan :

$\% X i=$ Rata-rata persentase angket-i pada assessment keterampilan proses sains pada materi Fluida Statis 
$\sum \%$ Xin $=$ Jumlah persentase angket-i assessment keterampilan proses sains pada materi Fluida Statis

$n \quad=$ Jumlah pertanyaan pada instrument.

\section{HASIL DAN PEMBAHASAN}

Uji coba instrument dilakukan dikelas yang berbeda yaitu kelas XI-B dan XI-C, hasil uji coba instrument KPS untuk hukum Newton dan fluida statis dengan memperhatikan validitas, reliabilitas, tingkat kesukaran dan daya beda instrument KPS fluida statis dengan rincian sebagai berikut diperoleh 18 soal untuk instrument KPS hukum Newton, dan 17 soal untuk. Untuk instrument KPS hukum Newton aspek KPS yang ditanyakan adalah Observasi 3 soal, Klasifikasi 4 soal, Interpretasi 2 soal, Prediksi 1 soal, Komunikasi 3 soal, Hipotesis 1 soal, Merencanakan Penelitian 1 soal, dan Menerapkan konsep 4 soal.

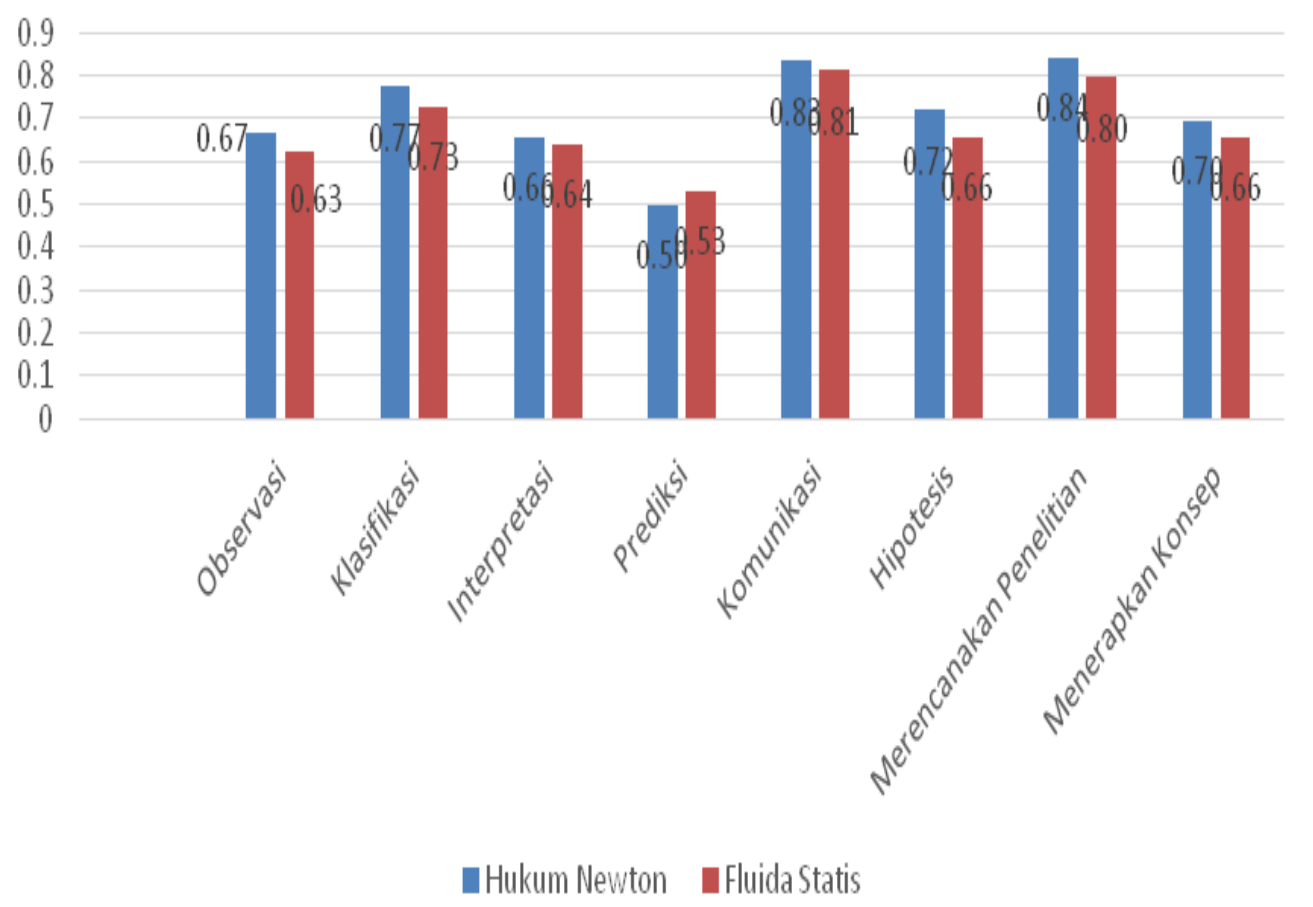

Gambar 1. Grafik Hasil Uji KPS Kelas X-A

Instrumen KPS fluida statis, aspek KPS yang ditanyakan adalah Observasi 2 soal, Klasifikasi 3 soal, Interpretasi 2 soal, Prediksi 2 soal, Komunikasi 2 soal, Hipotesis 2 soal, Merencanakan Penelitian 4 soal, dan Menerapkan konsep 1 soal. 
Tabel 3. Hasil Tanggapan Praktisi

\begin{tabular}{cccc}
\hline \multicolumn{4}{c}{ Penilaian Oleh Guru } \\
\hline No & Aspek & $\begin{array}{c}\text { Rerata } \\
\text { penilain }\end{array}$ & Kriteria \\
\hline 1. & Keterbacaan & $90 \%$ & $\begin{array}{c}\text { Sangat } \\
\text { layak }\end{array}$ \\
\hline 2. & $\begin{array}{c}\text { Kesesuaian } \\
\text { Isi Materi }\end{array}$ & $\begin{array}{c}\text { Sangat } \\
\text { layak }\end{array}$ \\
\hline
\end{tabular}

Dari instrument yang digunakan memiliki delapan aspek KPS yaitu Observasi, klasifikasi, interpretasi, prediksi, komunikasi, hipotesis, merencanakan penelitian dan menerapkan konsep. Walaupun aspek KOS yang digunakan oleh kedua instrument ini sama, tetapi banyak butir setiap aspek berbeda. Perbedaan banyak butir aspek ini sangat penting untuk melihat kekonsistensi jawaban siswa. Jika siswa benar-benar pamah salah satu aspek, maka diinstrumen yang lain harus bisa dijawab oleh siswa.

Tabel 4. Hasil Tanggapan Siswa

\begin{tabular}{cccc}
\hline \multicolumn{4}{c}{ Penilaian Oleh Siswa } \\
\hline No & Aspek & $\begin{array}{c}\text { Rerata } \\
\text { penilaian }\end{array}$ & Kriteria \\
\hline 1. & Keterbacaan & $80 \%$ & $\begin{array}{c}\text { Sangat } \\
\text { layak }\end{array}$ \\
\hline 2. & $\begin{array}{c}\text { Kesesuaian } \\
\text { Isi Materi }\end{array}$ & $80 \%$ & $\begin{array}{c}\text { Sangat } \\
\text { layak }\end{array}$ \\
\hline
\end{tabular}

Hasil penelitian (Grafik 1) diperoleh aspek KPS yang dimiliki siswa kelas XI-A dan konsistensi Aspek KPS yang dimiliki. Aspek yang paling dominan dimiliki oleh siswa kelas XI-A adalah KPS aspek komunikasi sebesar $80 \%$ baik pada materi hukum newton maupun fluida statis, diikuti oleh aspek merencanakan penelitia $80 \%$ dan klasifikasi $70 \%$.

Sedangkan aspek KPS lain yang dimiliki siswa MAN 2 kota Mataram kelas XI-A adalah observasi dan interpretasi konsisten sebesar 60\%, serta aspek prediksi $50 \%$. Untuk aspek hipotesis dan menerapkan konsep tidak konsisten $70 \%$ dan $60 \%$. Hasil ini menunjukan bahwa ada beberapa siswa yang tidak konsisten menjawab dengan benar pertanyan aspek hipotesis dan menerapkan konsep.

Selain itu untuk melihat bagaimana tanggapan guru dan siswa terhadap kegiatan isntremen KPS ini diberikan angket untuk melihat keterbacaan dan kesesuaian materi, angket ini diberikan pada guru fisika dan siswa. 
Respon guru dan murid terhadap kegiatan instrument KPS ini adalah sangat layak baik dari aspek isi materi maupun dari aspek keterbacaan. Ini menujukan bahwa instrument ini didukung oleh guru dan murid.

\section{SIMPULAN DAN SARAN}

Aspek KPS yang dimiliki oleh siswa MAN 2 Kota Mataram kelas XI-A adalah aspek observasi, mengelompokkan (klasifikasi), menafsirkan (interpretasi), meramalkan (prediksi), komunikasi, hipotesis, merencanakan percobaan, menerapkan konsep. Sedangkan respon guru dan siswa terhadap kegiatan instrument KPS ini adalah sangat layak baik dari aspek isi materi maupun dari aspek keterbacaan. Ini menujukan bahwa instrument ini didukung oleh guru dan murid.

Diharapkan kedepannya agar mengukur aspek KPS yang dimiliki siswa dengan materi yang berbeda agar terlihat konsistensi aspek KPS yang dimiliki siswa.

\section{DAFTAR PUSTAKA}

[1] Arumsari, Tiara Lusia. 2016. Pengembangan Instrumen Assessemnt Keterampilan Proses Sains Pada Materi Teori Tumbukan. Skripsi Universitas Lampung B. Uno, Hamzah dkk. 2014. Teori Assessment Pembelajaran. Jakarta: PT. Bumi Aksara

[2] Ilmi, Najwatul dkk. 2016. Jurnal Pengembangan Instrumen Penilaian Keterampilan Proses Sains Pada Pembelajaran Fisika SMA. Prosiding Seminar Nasional Fisika (E-Journal) SNF 2016. Volume V, Oktober 2016. P ISSN: 2339-0654. E - ISSN: 2476-9398

[3] Arikunto, Suharsimi. 2015. Dasar-dasar Evaluasi Pendidikan. Jakarta: PT. Bumi Aksara

[4] Koyan, I Wayan. 2011. Asesmen Dalam Pendidikan. Universitas Pendidikan Ganesa Press

[5] Arifin, Zainal. 2012. Evaluasi Pembelajaran. Jakarta: Direktorat Jenderal Pendidikan Islam kementrian Agama RI.

[6] Azwar S. 2001. Reliabilitas dan Validitas. Bandung: Remaja Rosdakarya

[7] B. Uno, Hamzah. 2014. Assessmen Pembelajaran. Jakarta: PT. Bumi Aksara

[8] Emzir. 2014. Metode Penelitian Kuantitatif \& Kualitatif Edisi Revisi. Jakarta: PT Raja Grafindo Persada

[9] Ratnaningsih. 2011. Analisis Item Soal Pilihan Ganda Ujian Akhir Semester Siswa Di Universitas Terbuka Dengan Pendekatan Teori Tes Klasik. Jurnal Pendidikan Terbuka dan Jarak Jauh 2 (12)

[10] Sani, R, A. 2015. Pembelajaran Saintifik Untuk Implementasi Kurikulum 2013. Jakarta. PT. Bumi Aksara.

[11] Setyosary, Punaji. 2015. Metode penelitian pendidikan dan Pengembangan. Jakarta: PT. Kharisma Putra Utama.

[12] Sudjana N. 2009. Penilaian Hasil Proses Belajar Mengajar. Bandung: PT Remaja Rosdakarya 
[13] Sugiyono. 2013.Metode Penelitian Kuantitatif Kualitatif dan $R \&$ D. Bandung Alfabeta

[14] Verawati Putu Sri, N. 2016. Meningkatkan Keterampilan Proses Sains Mahasiswa Melalui Pengembangan Program Pembelajaran Fisika Menggunakan Model Inkuiri. JURNAL Ilmiah Pendidikan Fisika VOL 1 NO 2 ISSN 2338-4417

[15] Widya wati, dkk. 2016. Pengembangan Rubrik Assessment Keterampilan Proses Sains Pada Pembelajaran Ipa Smp. JURNAL Ilmiah Pendidikan Fisika ' Al-Birune' 05 (1) (2016) 131-140. P-ISSN: 2303-1832: e-ISSN: 2503-023X

[16] Zamista, Alfama dkk. 2015. Jurnal Pengembangan Tes Keterampilan Proses Sains Materi Fluida Statis Kelas X SMA/MA. Seminar nasional fisika (2015) Volume IV, Oktober 2015. p-ISSN: 2339-0654. E-ISSN: 2476-9398. 